\title{
G

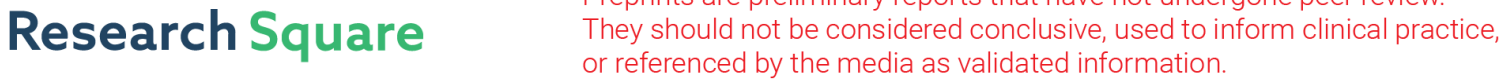 \\ Clinical relevance of CD70 expression in resected pancreatic cancer: prognostic value and therapeutic potential
}

Kota Nakamura

Nara Medical University

Masayuki Sho ( $\square$ m-sho@naramed-u.ac.jp )

Nara Medical University

Takahiro Akahori

Nara Medical University

Satoshi Nishiwada

Nara Medical University

Tomohiro Kunishige

Nara Medical University

Kenji Nakagawa

Nara Medical University

Minako Nagai

Nara Medical University

Tadataka Takagi

Nara Medical University

Taichi Terai

Nara Medical University

Naoya Ikeda

Nara Medical University

Research

Keywords: CD70, pancreatic cancer, metastasis, chemotherapy

Posted Date: October 7th, 2020

DOI: https://doi.org/10.21203/rs.3.rs-86059/v1

License: (1) (1) This work is licensed under a Creative Commons Attribution 4.0 International License.

Read Full License 
Version of Record: A version of this preprint was published at Pancreatology on April 1st, 2021. See the published version at https://doi.org/10.1016/j.pan.2021.01.013. 


\section{Abstract}

\section{Background}

Aberrant expression of CD70 in several malignancies is potentially associated with poor patient prognosis and could serve as a therapeutic target. However, the clinical relevance of CD70 expression in pancreatic cancer has not been thoroughly explored.

\section{Methods}

We evaluated CD70 expression in 166 surgical specimens obtained from human patients with pancreatic cancer. We analyzed the function of CD70 in proliferation and migration using pancreatic cancer cell lines with silenced CD70 expression.

\section{Results}

CD70 expression was positively stained in 42 patients (25\%). In the whole cohort, high CD70 expression was not associated with overall survival (OS: 33.1 vs. 40.8 months, $P=0.256$ ), although it was significantly associated with inferior OS in a population of patients that completed adjuvant chemotherapy $(P=0.027)$. Moreover, the incidence of hematogenous metastasis was significantly higher in patients with high CD70 expression than in those with low CD70 expression $(P=0.020)$. This finding was also statistically significant in multivariate analyses $(P=0.001)$. In vitro experiments demonstrated that CD70 expression contributed to cancer cell proliferation independently of gemcitabine treatment as well as cell migration. Furthermore, real-time polymerase chain reaction analysis of frozen surgical tissues showed a correlation between the expression of CD70 and mesenchymal markers.

\section{Conclusions}

CD70 expression in pancreatic cancer might be involved in hematogenous metastasis. Furthermore, our results imply that $C D 70$ overexpression can serve as a novel prognostic factor and a potential therapeutic target in patients who have completed adjuvant chemotherapy.

\section{Background}

Although surgery remains the only potentially curative option for pancreatic ductal adenocarcinoma (PDAC), less than $20 \%$ of patients are eligible to undergo curative oncologic resection $[1,2]$. In those who can undergo surgical resection, even in this most favorable cohort with resectable PDAC, the 5-year survival rate following tumor removal alone is less than $10 \%$ [3]. Therefore, pancreatic cancer remains a highly lethal malignancy [4].

Recently, several trials showed that postoperative administration of chemotherapy improved overall survival (OS); therefore, adjuvant chemotherapy has become the treatment of choice for patients with resected pancreatic cancer and has been generally accepted as the established standard of care $[3,5,6]$. 
However, as the survival in these patients remains unsatisfactory, additional strategies are clearly needed to achieve long-term survival.

CD70 is a type-II transmembrane protein and a member of the tumor-necrosis factor family $[7,8]$. CD70 expression is normally restricted to activated immune cells and is undetectable during the inactive state [7-9] However, CD70 is aberrantly expressed in different malignancies, including renal cell carcinoma (RCC) [7], leukemia and lymphoma [10, 11], non-small cell lung cancer $[12,13]$, breast cancer [14, 15], ovarian cancer [16], and melanoma [17]. Although the role of CD70 overexpression is not completely understood, CD70 activation has been implicated not only in local immunosuppression $[9,18]$, but also in tumor cell proliferation $[8,12]$, metastasis $[15,18]$, drug resistance $[10,16]$, and stemness $[11,15]$. Consequently, this surface protein could be associated with poor patient prognosis and could serve as a prognostic biomarker $[12,16]$. Furthermore, due to the lack of constitutive CD70 expression in normal tissues, CD70 may be an attractive therapeutic target [7, 9]. Indeed, CD70-directed antibody has shown antitumor activity in vitro $[9,12,19,20]$ and have demonstrated clinical responses against RCC and nonHodgkin's lymphoma in clinical trials [21-23].

Regarding pancreatic cancer, Ryan et al. reported that CD70 was aberrantly expressed in cancer tissues and that pancreatic cancer cell lines were sensitive to the anti-CD70 antibody-drug conjugate, SGN-75, both in vitro and in vivo [8]. Although the study suggested that blocking CD70 signals could be an appropriate therapeutic strategy, clinical data for CD70 expression in pancreatic cancer were completely lacking, and thus, its clinical significance remains unrevealed.

In this study, we aimed to elucidate the clinical significance of CD70 expression in patients with resectable pancreatic cancer and to determine whether CD70 can act as a novel prognostic biomarker and a potential therapeutic target.

\section{Methods}

\section{Patients}

Patients who underwent surgical PDAC resection at Nara Medical University Hospital between October 2008 and December 2014 were included in this study. Exclusion criteria included macroscopically incomplete resection, tumor histology other than PDAC, and patients who died within 30 days following surgery. Clinicopathological and treatment data for each patient were collected from their medical records. Stage classification was performed according to the seventh edition of the AJCC/UICC TNM classification. Para-aortic lymph node metastasis was recorded as a distant metastasis. Seventy-two out of 166 fresh cancer tissues were rapidly frozen at $-80^{\circ} \mathrm{C}$ until use. All resected specimens were fixed in $10 \%$ phosphate-buffered formalin and embedded in paraffin.

The neoadjuvant treatment regimen included gemcitabine and concomitant three-dimensional radiation of $54 \mathrm{~Gy}$, as previously reported [24]. After surgery, patients received intravenous gemcitabine with hepatic arterial-infusion chemotherapy [25] or intravenous gemcitabine alone, as adjuvant chemotherapy. 


\section{Immunohistochemistry (IHC)}

IHC was performed on 5- $\mu$ m-thick, routinely processed formalin-fixed paraffin-embedded (FFPE) sections of tumor specimens. Briefly, the slides were dewaxed, and heat-induced antigen retrieval was performed with a high-pH buffer for $20 \mathrm{~min}$ at $105^{\circ} \mathrm{C}$. Subsequently, endogenous peroxidase activity was quenched by incubating the slides in $3 \%$ hydrogen peroxide for $10 \mathrm{~min}$, and then the sections were incubated for 20 min with $2.5 \%$ normal horse serum. The sections were labeled for $30 \mathrm{~min}$ at room temperature with primary antibodies against human CD70 (clone 301731, diluted 1:40, R\&D Biosystems), CD4, CD8 (DAKO), and FoxP3 (ab22510, Abcam). After incubation with a secondary antibody (ImmPRESS HRP Anti-Rabbit IgG Polymer Detection Kit, Vector Laboratories), staining was performed using the ImmPACT DAB Kit (Vector Laboratories). Sections were counterstained with hematoxylin, dehydrated, and mounted. Positive controls (tonsil tissues) were included in each staining experiment. Membranous staining in lymphocytes was verified by staining an internal positive control. Slides were examined at $\times 400$ magnification, and five differently stained fields in each section were assessed by observers who were blinded to the patient information. CD70 expression was assessed in tumor cells, and CD70 expression was scored as high when $\geq 10 \%$ tumor cells showed membranous staining.

\section{Cell lines and reagents}

Pancreatic carcinoma cell lines (AsPC-1, BxPC-3, Capan-2, HPC-3, MIAPaCa-2, and PANC-1) were obtained from RIKEN BioResource Center. All tumor cells were maintained in Roswell Park Memorial Institute (RPMI) 1640 medium supplemented with 10\% heat-inactivated fetal bovine serum (FBS). Gemcitabine was purchased from Sawai Pharmaceutical Co., Ltd.

\section{Transient expression}

CD70 expression was silenced in pancreatic cancer cell lines using small interfering RNA (siRNA) against the target sequence, 5ל-CTGCGTCTCAGCTTCCACCAA-3 $\dot{c}$. The CD70 siRNA and a control siRNA were purchased from Qiagen. Cells were seeded into six-well plates at a density of $5 \times 10^{4}$ cells/well. When the cells reached cultured to $30-40 \%$ confluency, cells were transfected with $20 \mathrm{nM}$ of CD70 or control siRNA using Lipofectamine (Invitrogen). After $48 \mathrm{~h}$ of incubation, cells were harvested for polymerase chain reaction (PCR) and migration assay.

\section{Proliferation assays}

Proliferation assays were done with the CellTiter-Blue ${ }^{\circledR}$ cell viability kit (Promega), as manufacturer's instructions. Briefly, the cells were plated at $6 \times 10^{3}$ cells/well in 96-well plates and transfected with CD70 or control siRNA. Cells were cultured for 96 h, CellTiter-Blue ${ }^{\circledR}$ Cell Viability Reagent (Promega) was added to each well, and the cells were incubated for an additional $2 \mathrm{~h}$. CellTiter-Blue ${ }^{\circledR}$ fluorescence was detected with a SoftMax® Pro 5 device (Molecular Devices), using an excitation wavelength or $540 \mathrm{~nm}$ and an emission wavelength of $590 \mathrm{~nm}$. For the drug-sensitivity assays, $24 \mathrm{~h}$ after seeding, the cells were treated 
with gemcitabine $(10 \mu \mathrm{M})$ and incubated for an additional $72 \mathrm{~h}$. Three independent experiments were performed for all assays, and representative data are shown.

\section{In vitro cell-migration and cell-invasion assays}

For the cell-migration assays, $1.5 \times 10^{4}$ cells in RPMI 1640 medium were added to the upper compartment in cell culture inserts with an 8- $\mu \mathrm{m}$ pore size (Corning). The bottom chamber was filled with RPMI 1640 containing $10 \%$ FBS. After $24 \mathrm{~h}$, the upper surface of the inner chamber was wiped with cotton swabs, and cells on the bottom surface of the filter were stained and counted.

\section{Quantitative real-time PCR analysis}

Total RNA from cell lines and frozen specimens was isolated using the RNAspin Mini Kit (GE Healthcare). Complementary DNA synthesis from $1 \mu \mathrm{g}$ RNA was performed using the High Capacity cDNA Reverse Transcription Kit (Applied Biosystems). Real-time PCR was then performed with an ABI Prism 7700 Sequence Detection System (Applied Biosystems) or a StepOne Plus Real-Time PCR System (Applied Biosystems). TaqMan Gene Assays (Applied Biosystems) for CD70 (Hs00174297_m1), CDH1 (Hs01023894_m1), Vimentin (Hs00958111_m1), Snail (Hs00195591_m1), Slug (Hs00161904_m1), Twist (Hs01675818_m1), ß-catenin (Hs00355045_m1), and ß2-microglobulin (Hs00187842_m1) were used. The PCR thermal cycle conditions were as follows: initial step at $95^{\circ} \mathrm{C}$ for $10 \mathrm{~min}$, followed by 40 cycles of $95^{\circ} \mathrm{C}$ for 15 seconds and $60^{\circ} \mathrm{C}$ for $1 \mathrm{~min}$. Expression of $\beta 2$-microglobulin gene was measured as an internal reference with a standard curve to determine the integrity of RNA templates for all specimens. The ratio of the mRNA level of each gene was calculated as follows: (absolute copy number of each gene)/(absolute copy number of $\beta 2$-microglobulin).

\section{Statistical analysis}

Statistical analyses were performed using the JMP 13.0 statistical software program (SAS Institute, Inc.). The OS and cumulative incidence of each recurrence were calculated from the day of surgery to the day of death or recurrence. Survival was analyzed using Kaplan-Meier curves, and differences between groups were assessed using the log-rank test. Multivariate analyses were performed using the Cox proportional-hazards model. Continuous variables were determined as the median and range, and differences were evaluated using an unpaired Student's t test. Spearman's rank test was also used to determine correlations between two variables. A P value of less than 0.05 was considered to reflect a statistically significant difference.

\section{Results}

\section{CD70 expression in human pancreatic cancer cells}

In total, 166 patients who underwent PDAC resection were included in our study. To evaluate the significance of CD70 expression in human pancreatic cancer, we first performed IHC analysis on FFPE 
tissues. Figure 1 shows the staining pattern for CD70 expression in different tissues. CD70 was expressed mainly in the plasma membrane and cytoplasm of cancer cells (Fig. 1a, b). In several cases, tumor-infiltrating leukocytes that expressed CD70 were observed and used as internal controls (Fig. 1d). In normal tissues, positive staining was restricted to lymphoid tissues (tonsils, thymus, and spleen) and

gut-associated lymphoid cells. Positively stained tissues (tonsils) were used as a positive control (Fig. 1e). CD70 was not detected in the normal pancreas tissues, including acinar cells and normal glands (Fig. 1f).

\section{Patients characteristics}

Patient demographic, clinical, and histopathological variables are summarized in Table 1. Among the whole cohort, CD70 protein expression was confirmed in 42 patients (25\%). We found no significant association between neoadjuvant treatment and CD70 expression. A tumor with CD70 high expression tended to be located in the pancreatic body or tail. None of the other clinicopathological variables, such as age, sex, lymph node metastasis, and tumor grade differentiation, showed a significant relationship with CD70 expression.

\section{Survival analysis}

In the whole cohort, high CD70 expression was not associated with OS (33.1 vs. 40.8 months, $P=0.256$; Fig. 2a). We also found no differences in OS according to CD70 expression, neither in the upfront-surgery subgroup, nor in the neoadjuvant chemoradiation therapy subgroup (data not shown). As previously described, completion of adjuvant chemotherapy is one of the strongest prognostic factors associated with pancreatic cancer treatment [24]. To test whether CD70 expression could interact with the efficacy of adjuvant chemotherapy, we compared survival and recurrence data according to CD70 expression in patients that either did or did not complete adjuvant chemotherapy. High CD70 expression was significantly associated with inferior OS in the population of patients that completed adjuvant chemotherapy ( $N=110$, OS: 45.4 vs. 63.8 months, $P=0.027$; Fig. $2 b)$, whereas no such association was detected with the population of patients that did not complete adjuvant chemotherapy ( $N=56,0 S: 20.7$ vs. 14.9 months, $P=0.969$; Fig. 2c).

Moreover, the incidence of hematogenous metastasis was significantly higher in patients with high CD70 expression than in those with low CD70 expression ( $P=0.018$; Fig. 3a). In contrast, high CD70 expression was not associated with local recurrence $(P=0.218$; Fig. $3 b)$.

Multivariate analysis revealed that high CD70 expression, high T stage, para-aortic lymph node invasion, and incompletion of adjuvant chemotherapy were significant risk factors for hematogenous metastasis (Table 2). Moreover, significant prognostic factors for the entire adjuvant chemotherapy-completed population were carbohydrate antigen 19-9, a high T stage, the lymph node status, and CD70 expression $(P=0.011$, Supplementary Table 1$)$.

\section{Relative mRNA expression of CD70 in pancreatic cancer cell lines}


We next assessed relative CD70-expression levels in pancreatic cancer cell lines by real-time PCR. CD70 was relatively highly expressed in PANC-1, MIAPaCa-2, and AsPC-1 cells (Supplementary Fig. 1). With the exception of these cell lines, three out of the six pancreatic cell lines analyzed were almost negative for CD70 expression. Therefore, we conducted in vitro assays using the PANC-1 and MIAPaCa-2 pancreatic cancer cell lines.

\section{CD70 knockdown suppressed pancreatic cancer cell proliferation independently of gemcitabine}

Transient CD70 knockdown and gemcitabine therapy significantly reduced the growth of PANC-1 and MIAPaCa-2 cells (Fig. 4). Importantly, CD70 knockdown also removed enhanced proliferation in gemcitabine-treated cells. Overall, these results suggest that CD70 is involved in cell proliferation, and that blocking CD70 has the potential to suppress cell proliferation independently of gemcitabine treatment in pancreatic cancer cell lines.

\section{CD70 knockdown decreased migration in pancreatic cancer cell lines}

To elucidate the mechanism involved in the CD70-mediated metastatic increase, CD70 knockdown cells were used to study in vitro migration. Migration and transwell chamber assays showed that CD70 knockdown reduced PANC-1 and MIAPaCa-2 migration (Fig. 5). Using a migration assay, we found that CD70 induced pancreatic cancer cell migration in vitro.

\section{Correlation between CD70 and epithelial-to-mesenchymal transition (EMT)-related gene expression in human pancreatic cancer tissues}

To investigate how CD70 expression may be associated with a negative impact on prognosis, we focused on genes whose expression are associated with the EMT transition because of its broad role in metastasis and treatment resistance. We analyzed the association between CD70 expression and EMT markers in pancreatic cancer tissue by real-time PCR. In 20 available tissues from patients with positive IHC staining for CD70, CD70 expression significantly correlated with Vimentin $(r=0.640, P=0.004)$, Snail $(r=0.466, P=0.038)$, and Twist $(r=0.495, P=0.027)$ mRNA expression (Fig. 6$)$.

\section{Effect of CD70 knockdown on EMT-related gene expression in pancreatic cancer cell lines}

To investigate the possible association between CD70 and the EMT, and whether CD70 regulates EMT in pancreatic cancer cell lines, we knocked down CD70 expression in PANC-1 and MIAPaCa-2 cells using siRNA. The mRNA-expression levels of Vimentin, Snail, and Slug were significantly reduced by CD70 knockdown (Supplementary Fig. 2). Moreover, mRNA expression of $\beta$-catenin, the key molecule in the canonical Wnt-signaling pathway, was also significantly reduced by CD70 knockdown.

\section{Association between CD70 expression and tumor-infiltrating lymphocytes (TILs)}

Next, we investigated the immunomodulatory function of CD70 in pancreatic cancer. We performed IHC analysis of TILs, including CD4, CD8, and FoxP3. Our results showed that the numbers of tumor- 
infiltrating $\mathrm{CD}^{+}$and FoxP3 ${ }^{+} \mathrm{T}$ cells tended to be lower or higher in patients with high $\mathrm{CD} 70$ expression than in those with low CD70 expression ( $P=0.094$ and 0.075 , respectively; data not shown). However, these differences were not statistically significant.

\section{Discussion}

Recently, aberrant CD70 expression in cancer cells has been observed in several tumor types, including $\operatorname{RCC}[7,21]$, lymphocytic leukemia $[11,19]$, ovarian carcinoma [8][16], and breast cancer $[14,15]$. These findings suggest that blocking CD70-related signals could be an appropriate therapeutic strategy for some tumors $[9,19]$. Indeed, clinical trials are ongoing to evaluate CD70 as a therapeutic target, including the use of antibody-drug conjugates [22, 23] (clinical trials numbers NCT02216890 and NCT01015911) and enhanced antibody-dependent cellular cytotoxicity with an anti-CD70 monoclonal antibody [26] (clinical trial number NCT01813539). Regarding pancreatic cancer, a previous report showed that CD70 expression was found in $\geq 25 \%$ of cases [8,27], and CD70-overexpressing cell lines were also demonstrated to be sensitive to SGN-75 [8]. However, to our knowledge, clinical correlations between CD70 expression and pancreatic cancer have not been reported. In this study, we evaluated the prognostic impact of CD70 expression in PDAC after potential curative resection, using IHC. Our data showed a strong relationship between CD70 expression and hematogenous metastasis in patients with resected PDAC. Moreover, high CD70 expression was a worse prognostic indicator in the population of patients that completed adjuvant chemotherapy. Therefore, these findings suggest that the CD70-expression level is a useful prognostic biomarker and may serve as a novel therapeutic strategy against pancreatic cancer.

The recent emergence of modern chemotherapy has dramatically improved survival in patients with resectable pancreatic cancer $[5,6]$. In particular, those who completed the planned course of adjuvant chemotherapy comprised the most favorable cohort of patients with resectable PDAC $[24,28]$. However, despite complete tumor removal and administration of adjuvant chemotherapy, up to $70 \%$ of patients develop recurrence and die from metastatic disease $[5,6]$. Therefore, the detection of prognostic markers in patients with PDAC after adjuvant chemotherapy is still needed to achieve better outcomes. To address this critical clinical question, we conducted this study and found that high CD70 expression was an independent prognostic factor for shorter survival in resected PDAC. This finding may reflect an impaired capacity to respond to chemotherapy in CD70-positive pancreatic cancer cells. Our results suggested that CD70 knockdown suppressed the proliferation of gemcitabine-treated pancreatic cancer cells. Previous data demonstrated that CD70 expression was associated with drug resistance in different cancers [10, 16]. In a recent study, Jacobs et al. demonstrated the synergistic effect of cisplatin and an anti-CD70 antibody in non-small cell lung cancer [12]. Thus, combination therapy with cytotoxic chemotherapy and an anti-CD70 agent may also be a promising strategy for treating pancreatic cancer. Collectively, the study to evaluate the potential of targeting CD70 as a postoperative adjuvant treatment may be warranted. 
The results of this work showed that CD70 expression was associated with hematogenous metastases, which might be linked to the decreased migration capacities of pancreatic cancer cells with silenced CD70 expression. Flieswasser et al. previously reported that metastatic human pancreatic carcinomas have a higher percentage of CD70-positive cells than primary tumors [27]. Moreover, in breast cancer, CD70 expression markedly induced pulmonary metastasis [15]. Taken together, these results suggest that CD70 can impact hematogenous metastasis and that its role in regulating metastasis is independent of the tumor type. Therefore, to investigate how CD70 expression could contribute to hematogenous metastasis, we focused on the association between CD70 and EMT. Our findings showed a positive correlation between CD70 mRNA-expression levels and EMT-related gene expression in resected pancreatic cancer tissues. Moreover, our in vitro data showed that silencing CD70 reduced the expression of mesenchymal markers, which is suggestive of EMT. EMT plays a central role in embryogenesis and is well recognized for its close relationship with pancreatic cancer metastasis. Furthermore, EMT is also believed to enhance metastasis due to an increased migratory capacity of mesenchymal cells $[29,30]$. Several reports have shown that CD70 suppression can inhibit tumor cell migration [18], and CD70 activation has been implicated in cancer stemness [11] and EMT-related gene expression [15, 18]. We believe that the most likely explanation of our findings is that high CD70 expression in PDAC is associated with the upregulation of mesenchymal markers, which causes increased migratory capacity and metastasis.

There are several limitations to the current study. First, the present study is limited by its retrospective design in a single institution, and included a relatively small number of sample cases. Second, the precise fundamental function of CD70 remains to be fully elucidated. Although our findings suggested several potential mechanisms, the others may be involved. Therefore, further studies are required to validate our findings and to fully understand the underlying mechanisms of CD70 involved in PDAC.

\section{Conclusions}

CD70 may participate in the hematogenous metastasis of PDAC by regulating cell migration. Furthermore, CD70 overexpression was identified as a negative prognostic factor for patients with resected pancreatic cancer that were treated with adjuvant chemotherapy. These results suggest the potential of CD70 as a novel therapeutic target and that CD70-targeting agents are needed to improve survival in this subgroup.

\section{Abbreviations}

AJCC, American Joint Committee on Cancer; EMT, epithelial-to-mesenchymal transition; FBS, fetal bovine serum; FFPE, formalin-fixed paraffin-embedded; GEM, gemcitabine; IHC, immunohistochemistry; OS, overall survival; PCR, polymerase chain reaction; PDAC, pancreatic ductal adenocarcinoma; RCC, renal cell carcinoma; RPMI, Roswell Park Memorial Institute; siRNA, short-interfering RNA; UICC, Union for International Cancer Control 


\section{Declarations}

\section{Ethics approval and consent to participate}

Written informed consent was obtained from all the patients before treatment, according to our institutional guidelines. The study protocol was approved by the ethics committee of Nara Medical University (approval number: 2313).

\section{Consent for publication}

Not applicable

\section{Availability of data and materials}

The datasets supporting the conclusions of this article are included within the article (and its additional files).

\section{Competing interests}

The authors declare that they have no competing interests.

\section{Funding}

This study was supported by Grants-in-Aid for Scientific Research from the Ministry of Education, Culture, Sports, Science and Technology of Japan (grant numbers 19K18130, 19H03734, and 19K22668).

\section{Authors' contributions}

$\mathrm{KN}$ and $\mathrm{MS}$ conceived the study and designed the experiments. KN performed the $\mathrm{IHC}$ staining. $\mathrm{KN}$ and TK performed the in vitro experiments. TA, SN, KN, MN, TT, and SK managed the clinical samples. $\mathrm{KN}$ and MS analyzed the data. KN and MS wrote the manuscript. All authors read and approved the final manuscript.

\section{References}

1. Hidalgo M. Pancreatic cancer. N Engl J Med. 2010;362:1605-17.

2. Kleeff J, Korc M, Apte M, La Vecchia C, Johnson CD, Biankin AV, et al. Pancreatic cancer. Nat Rev Dis Prim. 2016;2:16022.

3. Oettle H, Neuhaus P, Hochhaus A, Hartmann JT, Gellert K, Ridwelski K, et al. Adjuvant chemotherapy with gemcitabine and long-term outcomes among patients with resected pancreatic cancer. JAMA. 2013;310:1473-81.

4. Rahib L, Smith BD, Aizenberg R, Rosenzweig AB, Fleshman JM, Matrisian LM. Projecting cancer incidence and deaths to 2030: the unexpected burden of thyroid, liver, and pancreas cancers in the United States. Cancer Res. 2014;74:2913-21. 
5. Uesaka K, Boku N, Fukutomi A, Okamura Y, Konishi M, Matsumoto I, et al. Adjuvant chemotherapy of S-1 versus gemcitabine for resected pancreatic cancer: a phase 3, open-label, randomised, noninferiority trial (JASPAC 01). Lancet. 2016;388:248-57.

6. Neoptolemos JP, Palmer DH, Ghaneh P, Psarelli EE, Valle JW, Halloran CM, et al. Comparison of adjuvant gemcitabine and capecitabine with gemcitabine monotherapy in patients with resected pancreatic cancer (ESPAC-4): a multicentre, open-label, randomised, phase 3 trial. Lancet. 2017;389:1011-24.

7. Law CL, Gordon KA, Toki BE, Yamane AK, Hering MA, Cerveny CG, et al. Lymphocyte activation antigen CD70 expressed by renal cell carcinoma is a potential therapeutic target for anti-CD70 antibody-drug conjugates. Cancer Res. 2006;66:2328-37.

8. Ryan MC, Kostner H, Gordon KA, Duniho S, Sutherland MK, Yu C, et al. Targeting pancreatic and ovarian carcinomas using the auristatin-based anti-CD70 antibody-drug conjugate SGN-75. Br J Cancer. 2010;103:676-84.

9. Jacobs J, Deschoolmeester V, Zwaenepoel K, Rolfo C, Silence K, Rottey S, et al. CD70: an emerging target in cancer immunotherapy. Pharmacol Ther. 2015;155:1-10.

10. Riether C, Schürch CM, Flury C, Hinterbrandner M, Drück L, Huguenin AL, et al. Tyrosine kinase inhibitor-induced CD70 expression mediates drug resistance in leukemia stem cells by activating Wnt signaling. Sci Transl Med. 2015;7:298ra119.

11. Riether C, Schürch CM, Bührer ED, Hinterbrandner M, Huguenin AL, Hoepner S, et al. CD70/CD27 signaling promotes blast stemness and is a viable therapeutic target in acute myeloid leukemia. J Exp Med. 2017;214:359-80.

12. Jacobs J, Deschoolmeester V, Rolfo C, Zwaenepoel K, Van den Bossche J, Deben C, et al. Preclinical data on the combination of cisplatin and anti-CD70 therapy in non-small cell lung cancer as an excellent match in the era of combination therapy. Oncotarget. 2017;8:74058-67.

13. Jacobs J, Zwaenepoel K, Rolfo C, Van Den Bossche J, Deben C, Silence K, et al. Unlocking the potential of CD70 as a novel immunotherapeutic target for non-small cell lung cancer. Oncotarget. 2015;6:13462-75.

14. Petrau C, Cornic M, Bertrand P, Maingonnat C, Marchand V, Picquenot JM, et al. CD70: A potential target in breast cancer? J Cancer. 2014;5:761-4.

15. Liu L, Yin B, Yi Z, Liu XJ, Hu ZQ, Gao WC, et al. Breast cancer stem cells characterized by CD70 expression preferentially metastasize to the lungs. Breast Cancer. 2018;25:706-16.

16. Liu N, Sheng X, Liu Y, Zhang X, Yu J. Increased CD70 expression is associated with clinical resistance to cisplatin-based chemotherapy and poor survival in advanced ovarian carcinomas. Onco Targets Ther. 2013;6:615-9.

17. Pich C, Sarrabayrouse G, Teiti I, Mariamé B, Rochaix P, Lamant L, et al. Melanoma-expressed CD70 is involved in invasion and metastasis. Br J Cancer. 2016;114:63-70.

18. Ge H, Mu L, Jin L, Yang C, Chang YE, Long Y, et al. Tumor associated CD70 expression is involved in promoting tumor migration and macrophage infiltration in GBM. Int J Cancer. 2017;141:1434-44. 
19. Buchan SL, Rogel A, Al-Shamkhani A. The immunobiology of CD27 and OX40 and their potential as targets for cancer immunotherapy. Blood. 2018;131:39-48.

20. Silence K, Dreier T, Moshir M, Ulrichts P, Gabriels SME, Saunders M, et al. ARGX-110, a highly potent antibody targeting CD70, eliminates tumors via both enhanced ADCC and immune checkpoint blockade. MAbs. 2014;6:523-32.

21. Pal SK, Forero-Torres A, Thompson JA, Morris JC, Chhabra S, Hoimes CJ, et al. A phase 1 trial of SGN-CD70A in patients with CD70-positive, metastatic renal cell carcinoma. Cancer. 2019;125:112432.

22. Tannir NM, Forero-Torres A, Ramchandren R, Pal SK, Ansell SM, Infante JR, et al. Phase I doseescalation study of SGN-75 in patients with CD70-positive relapsed/refractory non-Hodgkin lymphoma or metastatic renal cell carcinoma. Invest New Drugs. 2014;32:1246-57.

23. Phillips T, Barr PM, Park SI, Kolibaba K, Caimi PF, Chhabra S, et al. A phase 1 trial of SGN-CD70A in patients with CD70-positive diffuse large B cell lymphoma and mantle cell lymphoma. Invest New Drugs. Investigational New Drugs; 2019;37:297-306.

24. Sho M, Akahori T, Tanaka T, Kinoshita S, Nagai M, Nishiwada S, et al. Optimal indication of neoadjuvant chemoradiotherapy for pancreatic cancer. Langenbecks Arch Surg. 2015;400:477-85.

25. Sho M, Tanaka T, Yamada T, Nomi T, Akahori T, Doh J, et al. Novel postoperative adjuvant strategy prevents early hepatic recurrence after resection of pancreatic cancer. J Hepatobiliary Pancreat Sci. 2011;18:235-40.

26. Aftimos P, Rolfo C, Rottey S, Offner F, Bron D, Maerevoet M, et al. Phase I dose-escalation study of the anti-CD70 antibody ARGX-110 in advanced malignancies. Clin Cancer Res. 2017;23:6411-20.

27. Flieswasser T, Camara-Clayette V, Danu A, Bosq J, Ribrag V, Zabrocki P, et al. Screening a broad range of solid and haematological tumour types for CD70 expression using a uniform IHC methodology as potential patient stratification method. Cancers. 2019;11:E1611.

28. Valle JW, Palmer D, Jackson R, Cox T, Neoptolemos JP, Ghaneh P, et al. Optimal duration and timing of adjuvant chemotherapy after definitive surgery for ductal adenocarcinoma of the pancreas: Ongoing lessons from the ESPAC-3 study. J Clin Oncol. 2014;32:504-12.

29. Gaianigo N, Melisi D, Carbone C. EMT and treatment resistance in pancreatic cancer. Cancers. 2017;9:E122.

30. Krebs AM, Mitschke J, Losada ML, Schmalhofer O, Boerries M, Busch H, et al. The EMT-activator Zeb1 is a key factor for cell plasticity and promotes metastasis in pancreatic cancer. Nat Cell Biol. 2017;19:518-29.

\section{Tables}




\begin{tabular}{|c|c|c|c|c|c|c|}
\hline \multirow[b]{2}{*}{ Age, y } & & \multicolumn{2}{|c|}{$\begin{array}{l}\text { CD70 High } \\
(\mathrm{n}=42)\end{array}$} & \multicolumn{2}{|c|}{$\begin{array}{l}\text { CD70 Low } \\
(n=124)\end{array}$} & \multirow{2}{*}{$\begin{array}{l}P \\
0.788\end{array}$} \\
\hline & & 69 & $(47-84)$ & 70 & $(36-87)$ & \\
\hline \multirow[t]{2}{*}{ Gender } & Male & 27 & 64.3 & 69 & 55.7 & 0.327 \\
\hline & Female & 15 & 35.7 & 55 & 44.4 & \\
\hline CA19-9 (U/mL) & & 106 & $(1-4581)$ & 89 & $(1-1903)$ & 0.770 \\
\hline \multirow[t]{2}{*}{ Neoadjuvant treatment } & Present & 28 & 66.7 & 70 & 56.5 & 0.245 \\
\hline & Absent & 14 & 33.3 & 54 & 43.6 & \\
\hline \multirow[t]{3}{*}{ Location } & Head & 20 & 47.6 & 84 & 67.7 & 0.064 \\
\hline & Body / Tail & 21 & 50.0 & 39 & 31.5 & \\
\hline & Head / Body /Tail & 1 & 2.4 & 1 & 0.8 & \\
\hline \multirow[t]{2}{*}{ pT (AGCC/UICC) } & $\mathrm{T} 1 / 2$ & 8 & 19.1 & 17 & 13.7 & 0.403 \\
\hline & $\mathrm{T} 3 / 4$ & 34 & 81.0 & 107 & 86.3 & \\
\hline \multirow[t]{2}{*}{ pN (AGCC/UICC) } & NO & 31 & 73.8 & 77 & 62.1 & 0.169 \\
\hline & N1 & 11 & 26.2 & 47 & 37.9 & \\
\hline \multirow[t]{2}{*}{ pM (AGCC/UICC) } & Mo & 41 & 97.6 & 118 & 95.2 & 0.680 \\
\hline & M1 & 1 & 2.4 & 6 & 4.8 & \\
\hline \multirow[t]{4}{*}{ Differentiation } & Well & 24 & 57.1 & 67 & 54.0 & 0.895 \\
\hline & Moderately & 14 & 33.3 & 47 & 37.9 & \\
\hline & Poorly & 3 & 7.1 & 6 & 4.8 & \\
\hline & Other & 1 & 2.4 & 4 & 3.2 & \\
\hline \multirow[t]{2}{*}{ Resection margin } & Free & 35 & 83.3 & 105 & 84.7 & 0.836 \\
\hline & Microscopic residual & 7 & 16.7 & 19 & 15.3 & \\
\hline \multirow[t]{2}{*}{ Adjuvant chemotherapy } & Completion & 32 & 76.2 & 78 & 62.9 & 0.116 \\
\hline & Incompletion & 10 & 23.8 & 46 & 37.1 & \\
\hline
\end{tabular}


Table 2 Risk factor for hematogenous metastasis

\begin{tabular}{|c|c|c|c|c|c|c|c|}
\hline & & \multicolumn{3}{|c|}{ Univariate analysis } & \multicolumn{3}{|c|}{ Multivariate analysis } \\
\hline & & $\mathrm{HR}$ & $95 \% \mathrm{Cl}$ & $P$ & $\mathrm{HR}$ & $95 \% \mathrm{Cl}$ & $P$ \\
\hline \multirow[t]{2}{*}{ CA19-9 (U/mL) } & $\leq 37$ & 1 & & & & & \\
\hline & $>38$ & 1.32 & $\begin{array}{l}0.84- \\
2.16\end{array}$ & 0.229 & & & \\
\hline \multirow[t]{2}{*}{ pT (AGCC/UICC) } & $\mathrm{T} 1 / 2$ & 1 & & & 1 & & \\
\hline & T3/4 & 2.18 & $\begin{array}{l}1.18- \\
4.49\end{array}$ & 0.011 & 2.39 & $\begin{array}{l}1.20- \\
5.48\end{array}$ & 0.011 \\
\hline \multirow[t]{2}{*}{ pN (AGCC/UICC) } & NO & 1 & & & & & \\
\hline & $\mathrm{N} 1$ & 1.34 & $\begin{array}{l}0.85- \\
2.08\end{array}$ & 0.202 & & & \\
\hline \multirow[t]{2}{*}{ pM (AGCC/UICC) } & MO & 1 & & & 1 & & \\
\hline & M1 & 3.43 & $\begin{array}{l}1.20- \\
7.72\end{array}$ & 0.025 & 4.23 & $\begin{array}{l}1.43- \\
10.09\end{array}$ & 0.012 \\
\hline \multirow[t]{2}{*}{ Resection margin } & Free & 1 & & & 1 & & \\
\hline & $\begin{array}{l}\text { Microscopic } \\
\text { residual }\end{array}$ & 2.01 & $\begin{array}{l}1.14- \\
3.36\end{array}$ & 0.017 & 1.24 & $\begin{array}{l}0.69- \\
2.11\end{array}$ & 0.463 \\
\hline \multirow{2}{*}{$\begin{array}{l}\text { Adjuvant } \\
\text { chemotherapy }\end{array}$} & Completion & 1 & & & 1 & & \\
\hline & Incompletion & 3.27 & $\begin{array}{l}2.09- \\
5.05\end{array}$ & $<0.001$ & 3.48 & $\begin{array}{l}2.14- \\
5.60\end{array}$ & $<0.001$ \\
\hline \multirow[t]{2}{*}{ CD70 expression } & Low & 1 & & & 1 & & \\
\hline & High & 1.73 & $\begin{array}{l}1.08- \\
2.71\end{array}$ & 0.018 & 2.26 & $\begin{array}{l}1.38- \\
3.62\end{array}$ & 0.001 \\
\hline
\end{tabular}

Figures 


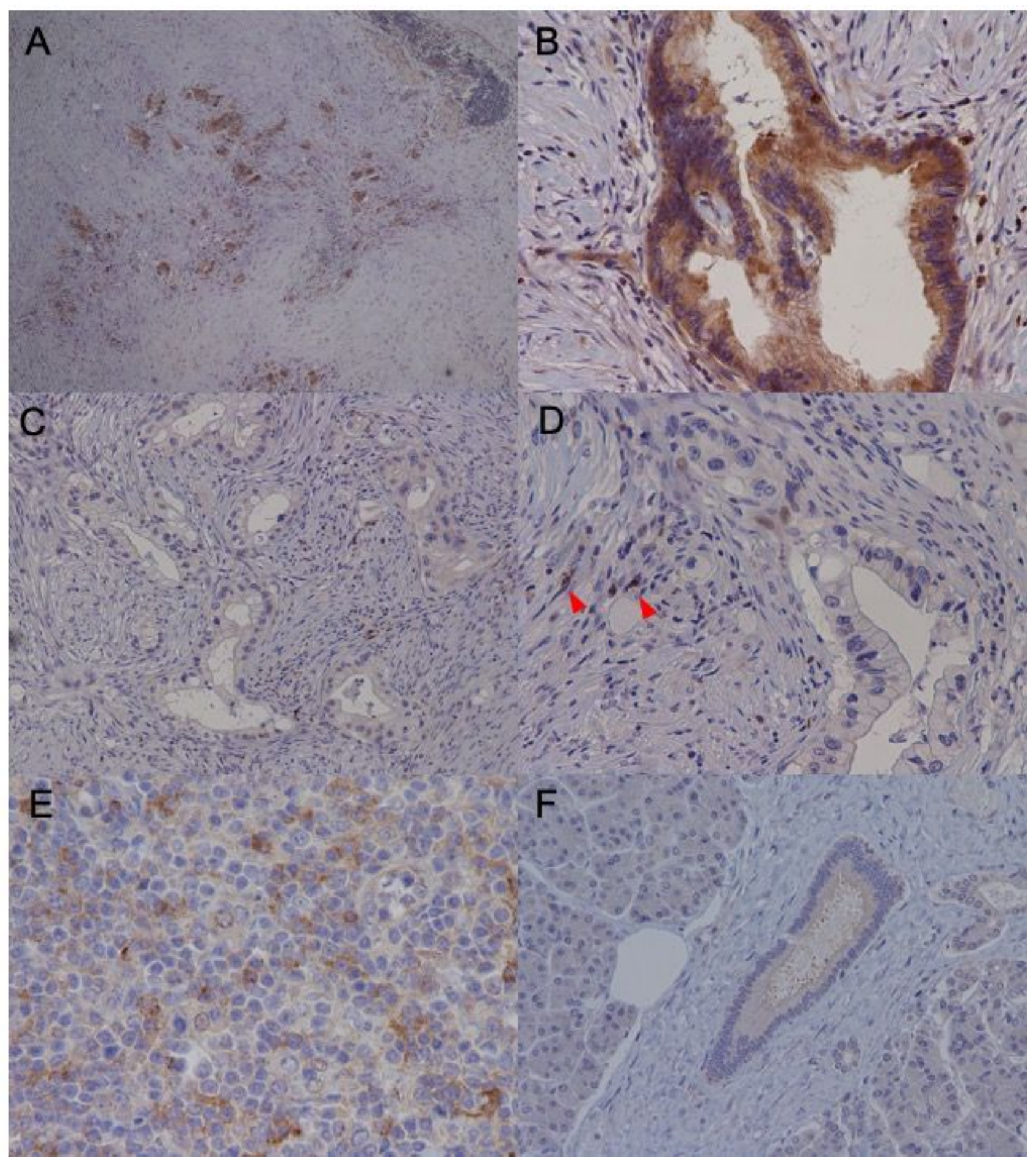

\section{Figure 1}

Representative images of CD70 expression after IHC staining. (a, b) Positive staining. (c) Negative staining. (d) TILs expressing CD70 were used as internal controls (arrows). (e) Tonsil tissues were used as a positive control. (f) CD70 expression was not detected in normal pancreatic tissues (including acinar cells and normal glands). 


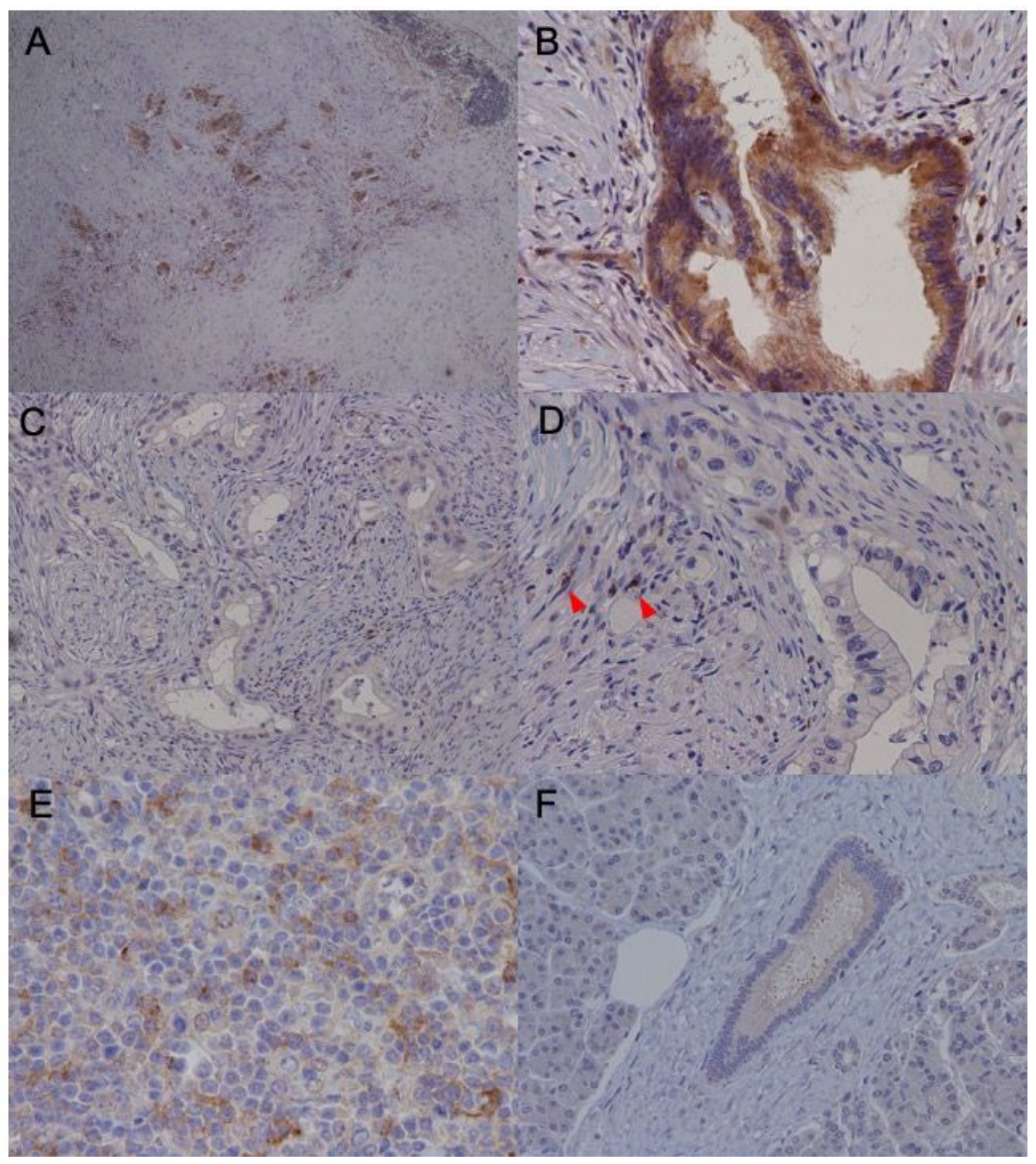

\section{Figure 1}

Representative images of CD70 expression after IHC staining. (a, b) Positive staining. (c) Negative staining. (d) TILs expressing CD70 were used as internal controls (arrows). (e) Tonsil tissues were used as a positive control. (f) CD70 expression was not detected in normal pancreatic tissues (including acinar cells and normal glands). 

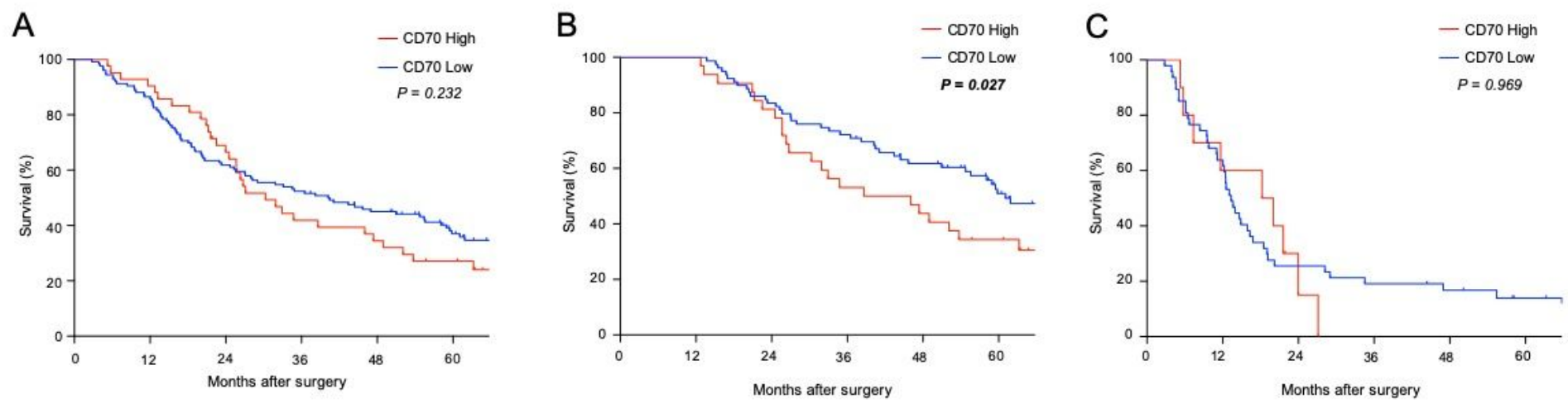

Figure 2

Effect of completing adjuvant chemotherapy on OS in patients with PDAC. (a) OS analysis. (b) OS of a cohort of patients that completed adjuvant chemotherapy. (c) OS of a cohort of patients that did not complete adjuvant chemotherapy.
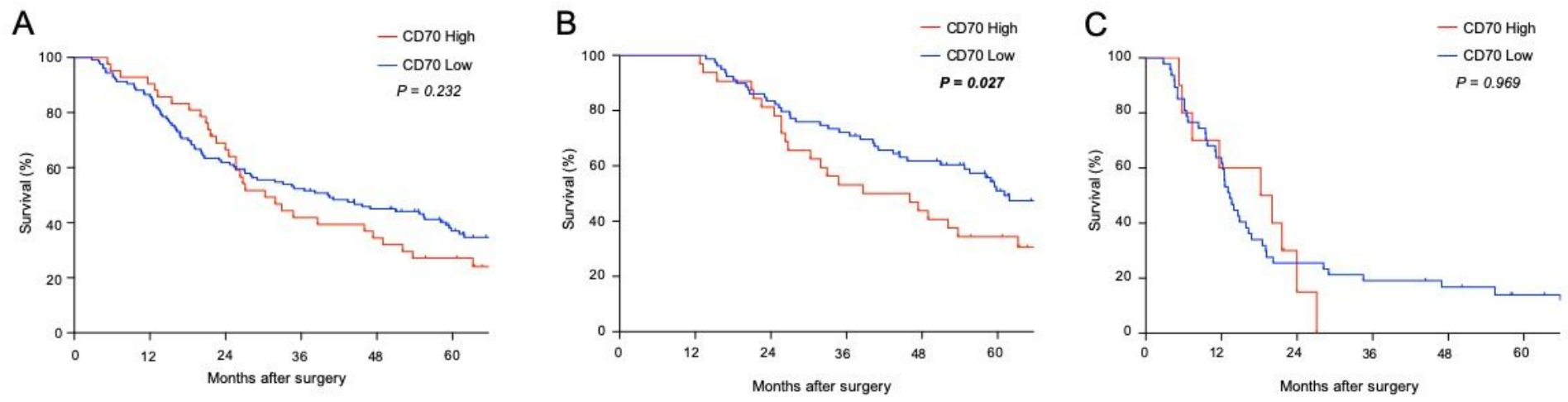

Figure 2

Effect of completing adjuvant chemotherapy on OS in patients with PDAC. (a) OS analysis. (b) OS of a cohort of patients that completed adjuvant chemotherapy. (c) OS of a cohort of patients that did not complete adjuvant chemotherapy.
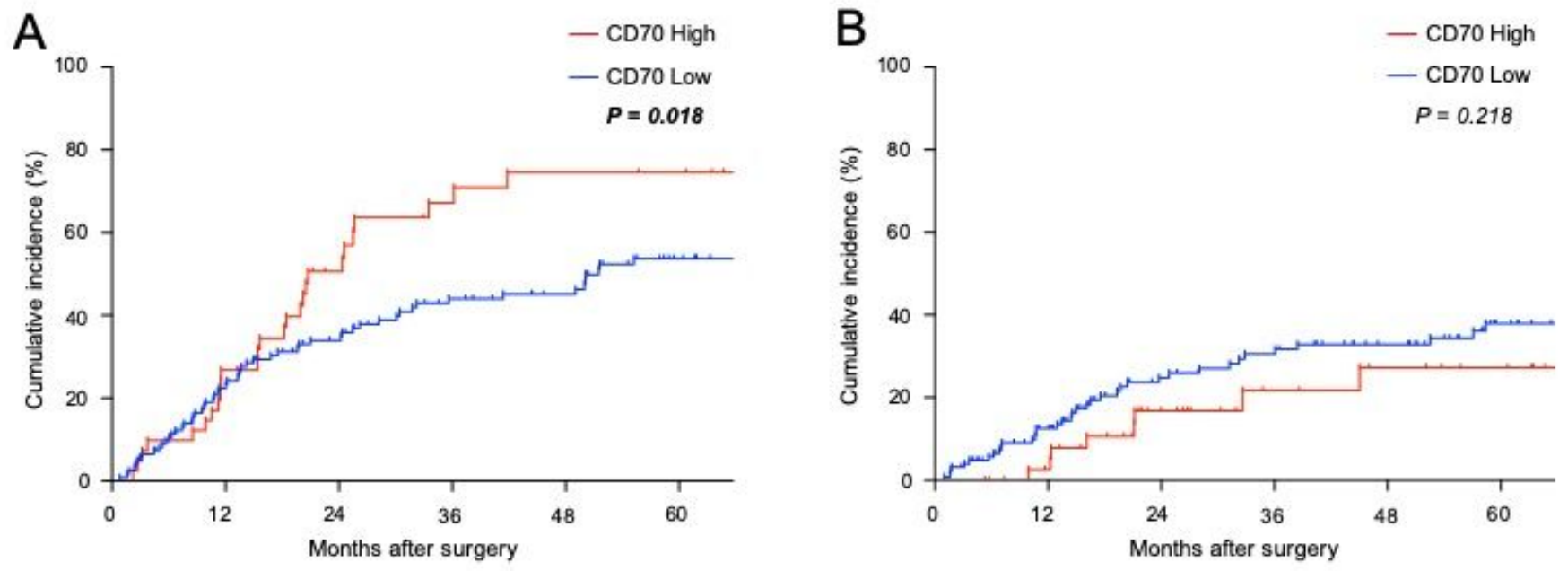


\section{Figure 3}

Cumulative incidences of hematogenous metastasis and local recurrence. (a) Cumulative incidence of hematogenous metastasis. (b) Cumulative incidence of local recurrence
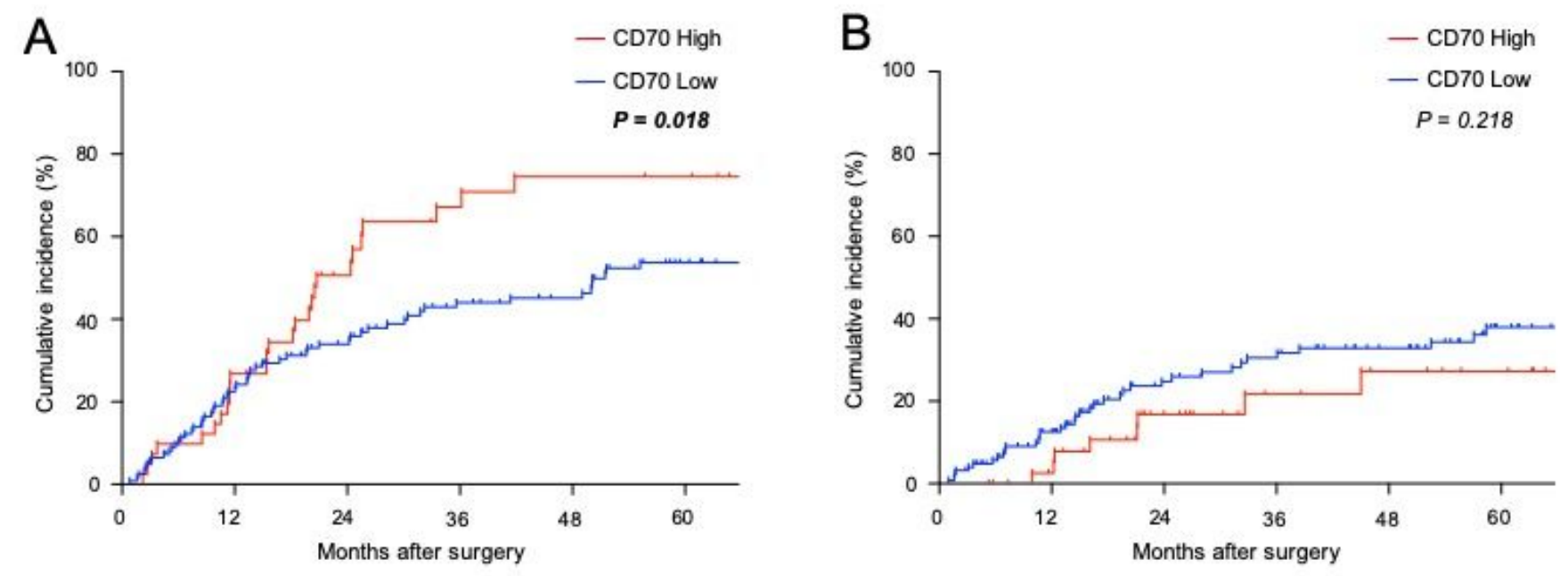

\section{Figure 3}

Cumulative incidences of hematogenous metastasis and local recurrence. (a) Cumulative incidence of hematogenous metastasis. (b) Cumulative incidence of local recurrence 
PANC-1

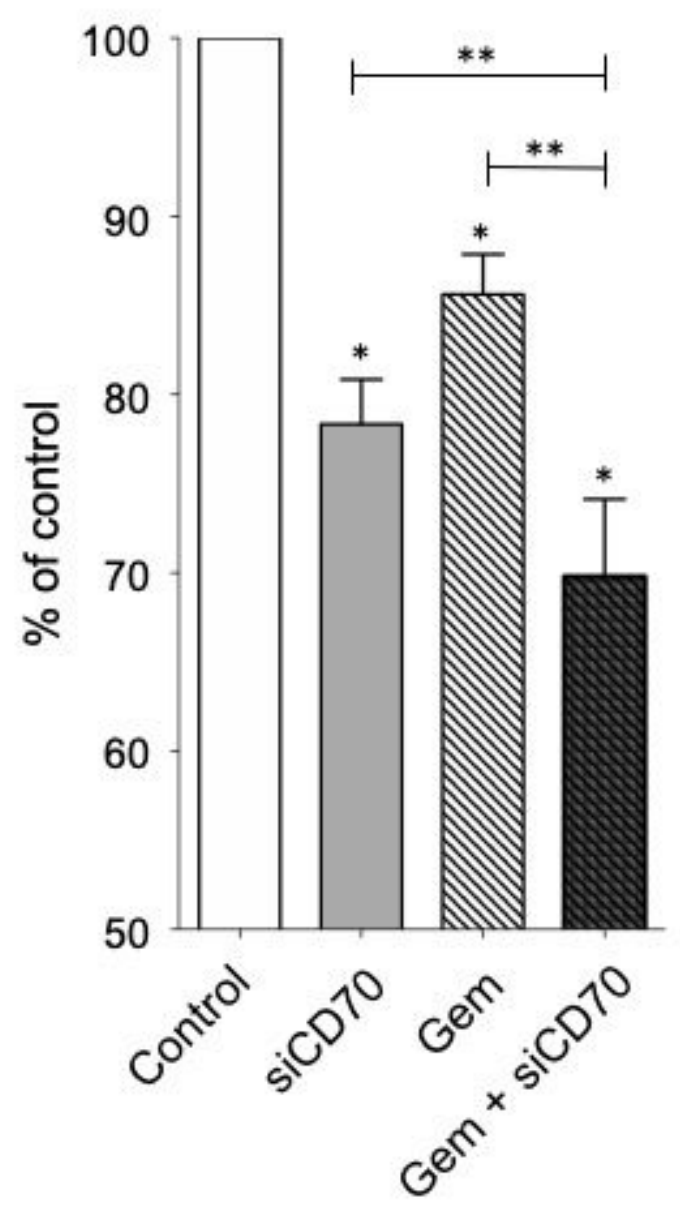

MIAPaca-2

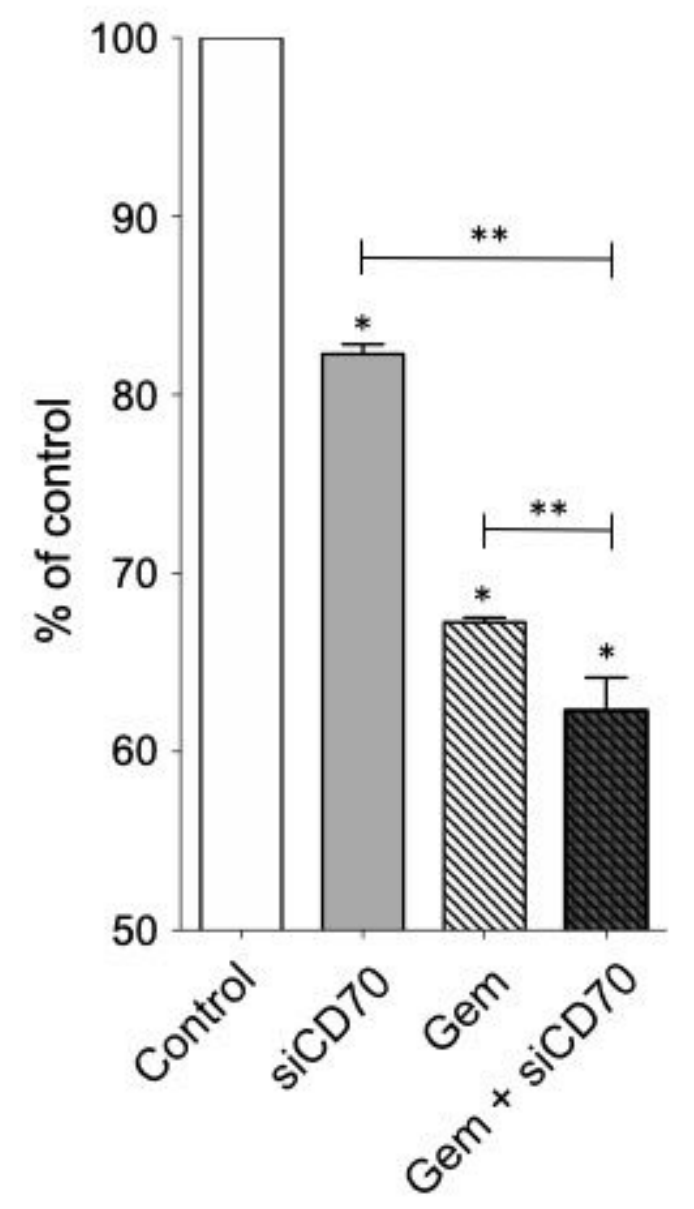

Figure 4

Significant reduction in the growth of PANC-1 and MIAPaCa-2 cells after CD70 knockdown and gemcitabine treatment. Notably, CD70 knockdown suppressed proliferation in gemcitabine-treated cells. ${ }^{\star} \mathrm{P}<0.05$ vs. control. ${ }^{*} \mathrm{P}<0.05$ vs. control 
PANC-1

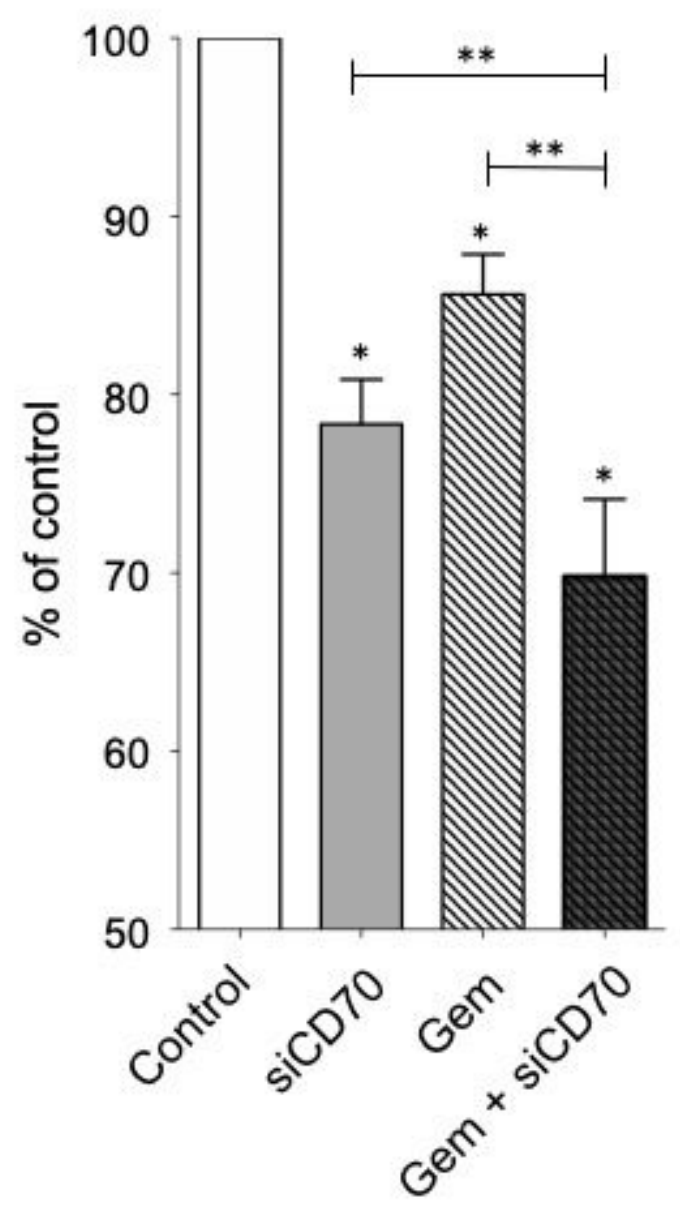

MIAPaca-2

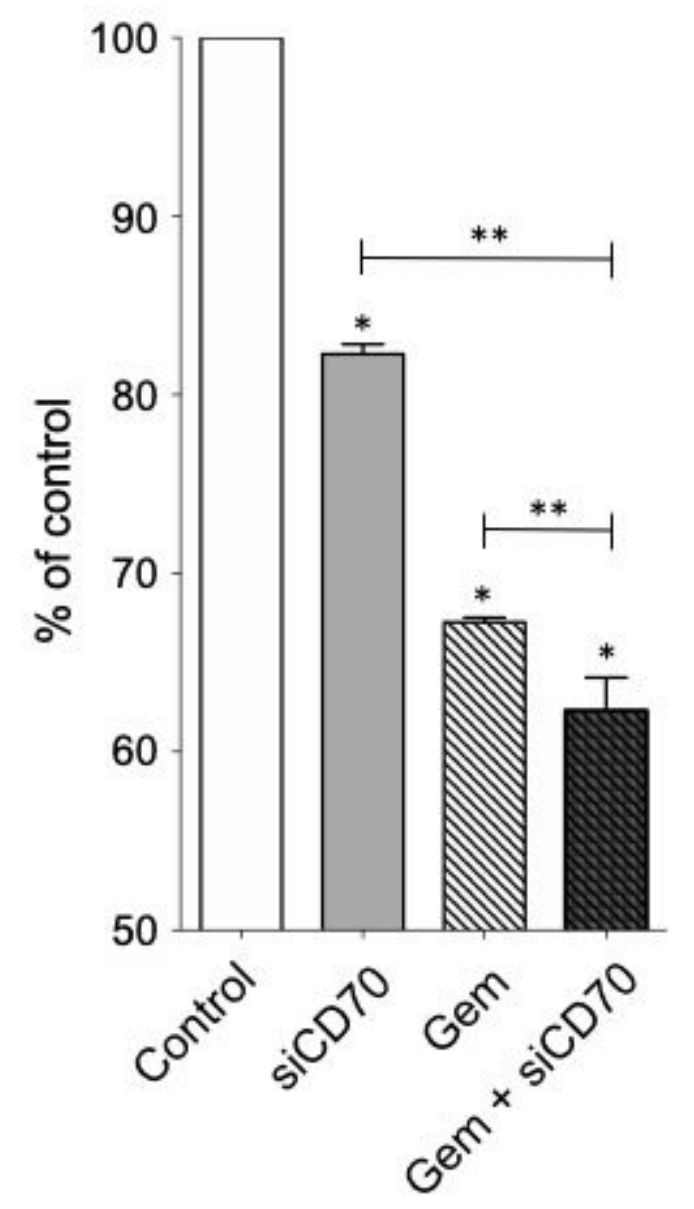

Figure 4

Significant reduction in the growth of PANC-1 and MIAPaCa-2 cells after CD70 knockdown and gemcitabine treatment. Notably, CD70 knockdown suppressed proliferation in gemcitabine-treated cells. ${ }^{\star} \mathrm{P}<0.05$ vs. control. ${ }^{*} \mathrm{P}<0.05$ vs. control 

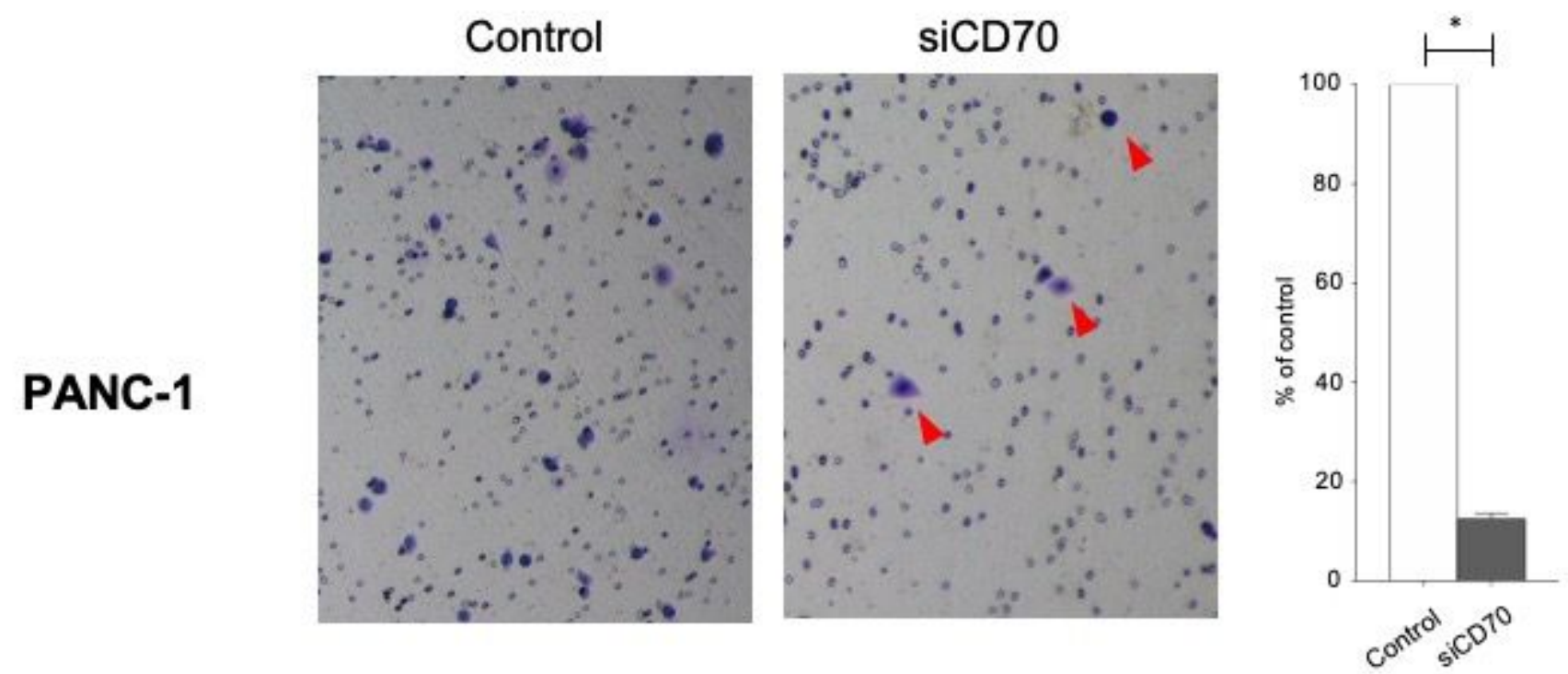

\section{MIAPaca-2}
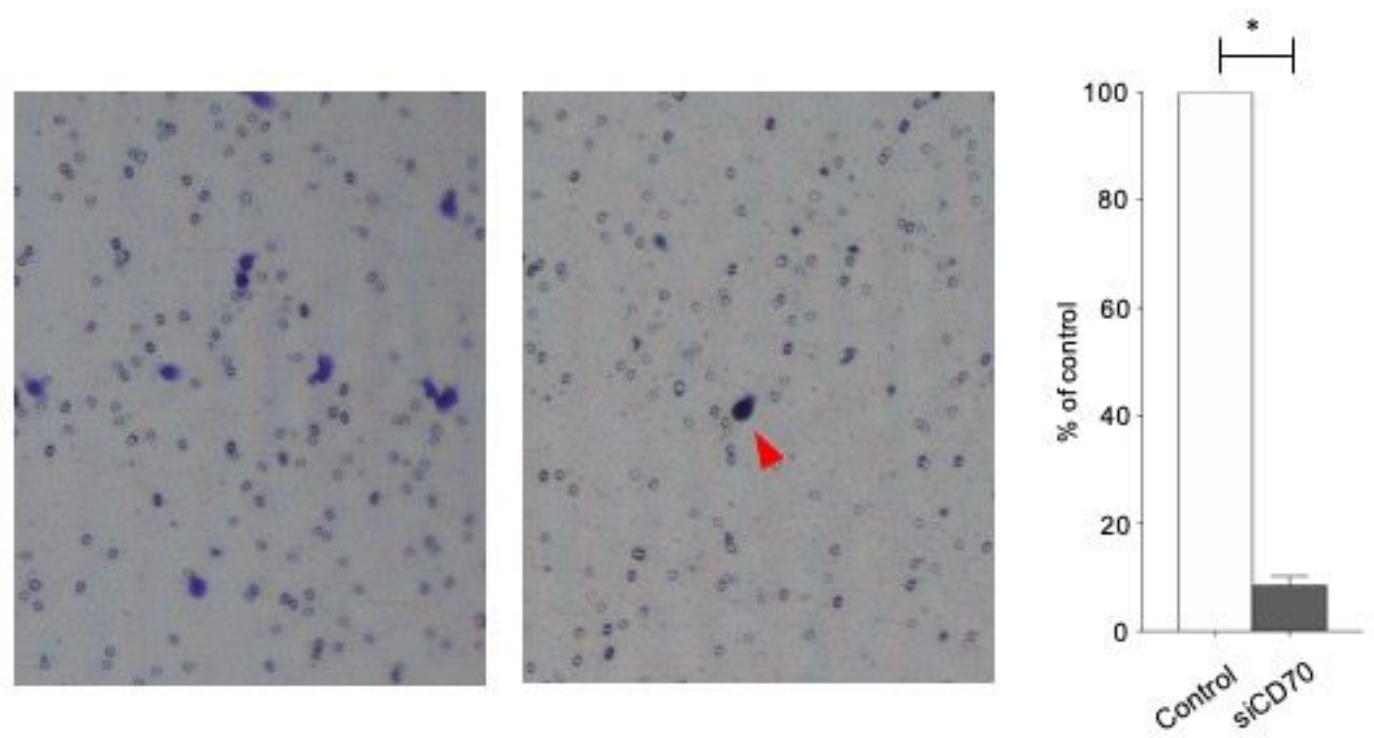

Figure 5

Cell-migration assays showing that CD70 knockdown significantly reduced PANC-1 and MIAPaCa-2 migration. ${ }^{*} \mathrm{P}<0.05$ 


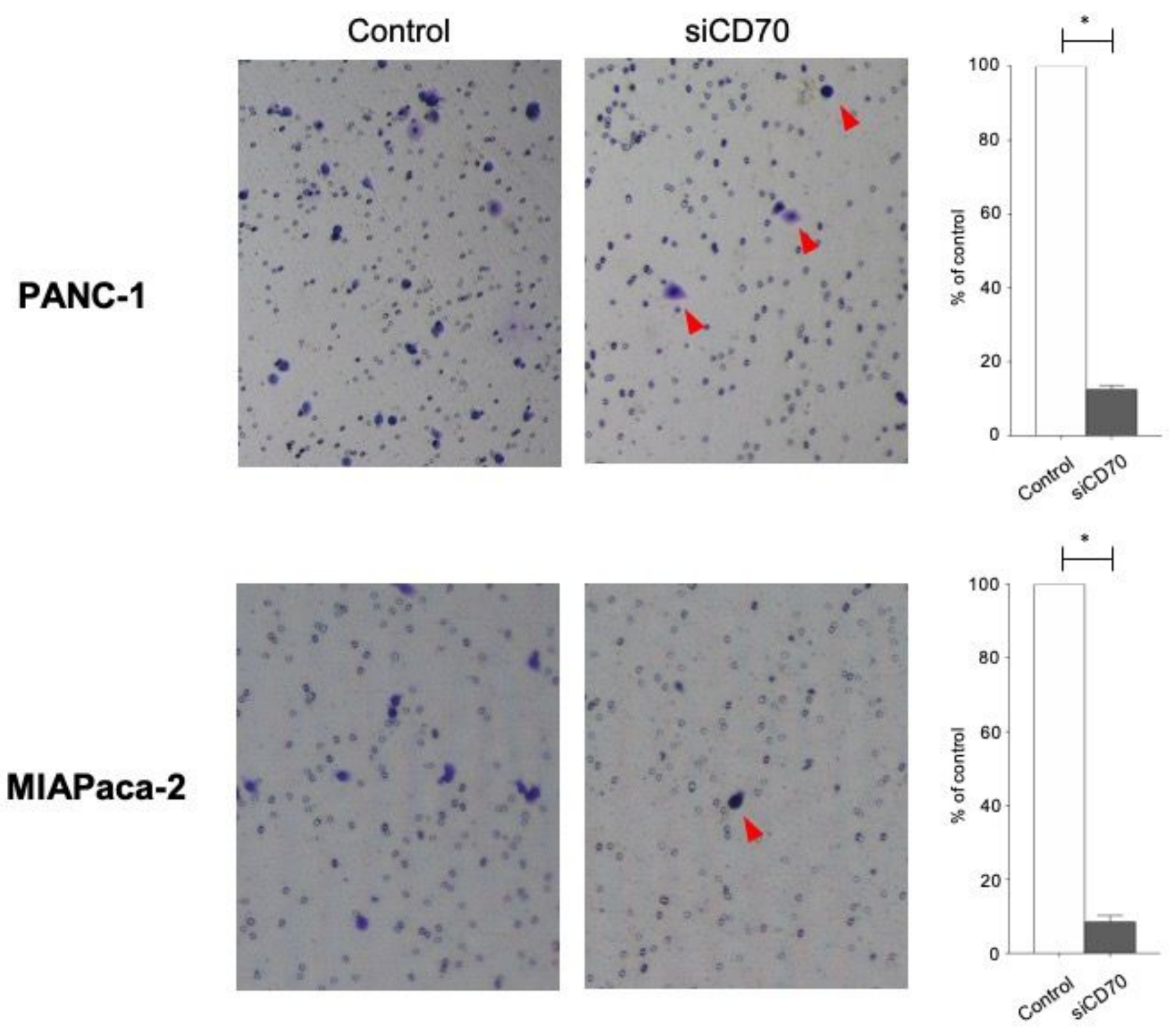

Figure 5

Cell-migration assays showing that CD70 knockdown significantly reduced PANC-1 and MIAPaCa-2 migration. $* \mathrm{P}<0.05$
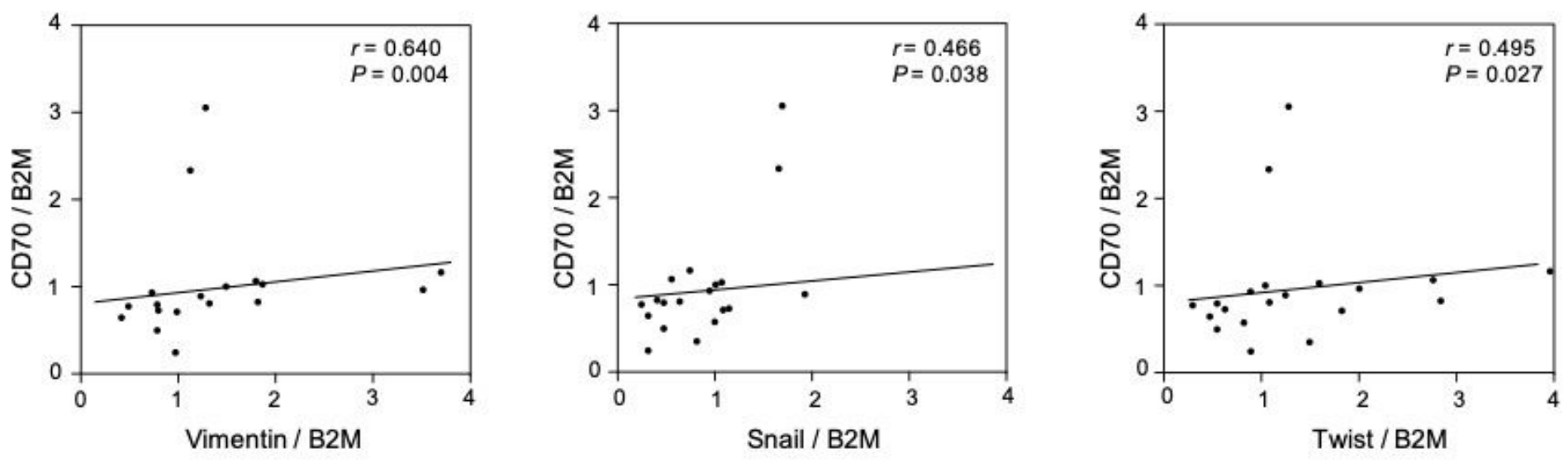
Figure 6

Real-time PCR analysis of frozen surgical tissues in patients with positive IHC staining for CD70. CD70 expression significantly correlated with Vimentin, Snail, and Twist mRNA expression.
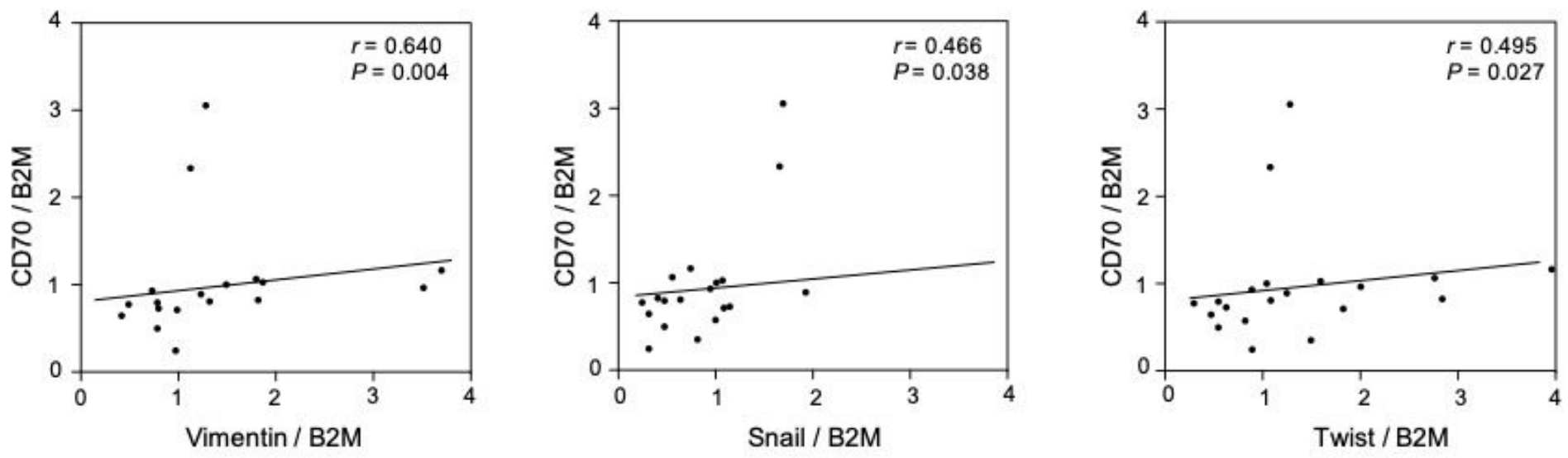

Figure 6

Real-time PCR analysis of frozen surgical tissues in patients with positive IHC staining for CD70. CD70 expression significantly correlated with Vimentin, Snail, and Twist mRNA expression.

\section{Supplementary Files}

This is a list of supplementary files associated with this preprint. Click to download.

- SupplementaryFigure2.jpg

- SupplementaryFigure2.jpg

- SupplementaryFigure1.jpg

- SupplementaryFigure1.jpg

- SupplementaryTable1.docx

- SupplementaryTable1.docx 